\title{
Encapsulation of Freeze-dried Propolis Powder: Study of in vitro Disintegration and Dissolution
}

\author{
Wan Nurul Huda Wan Zainal*, Enidran Loganathan, Thavakumara Ganesan \\ Faculty of Chemical and Process Engineering Technology, Universiti Malaysia Pahang, Lebuhraya Tun Razak, 26300 Gambang, \\ Kuantan, Pahang, MALAYSIA.
}

\begin{abstract}
Propolis is a resinous material collected by bees from various plant sources. Propolis has been used since ancient times for medicinal purposes. In this study, the propolis extracts were dried using a freeze-drying technique to preserve its medicinal properties. The effect of different freezing temperatures on the yield and propolis powder flow ability characteristics was evaluated. The potential of propolis powder to be encapsulated in hard gelatin capsules and hard hydroxypropyl methylcellulose (HPMC) capsules were investigated. The mass uniformity, in vitro disintegration and dissolution performance of the propolis powder in hard gelatine capsules and hard HPMC capsules were determined after encapsulation. The amount of propolis powder produced after freeze-drying decreased with decreasing of freezing temperature from $-50^{\circ} \mathrm{C}$ to $-80^{\circ} \mathrm{C}$. Propolis powder obtained at $-80^{\circ} \mathrm{C}$ of freezing temperature showed excellent flow ability characteristics. The average mass of propolis powder in hard gelatine capsules and the propolis powder in hard HPMC capsules was $0.5578 \pm 0.019 \mathrm{~g}$ and $0.5559 \pm 0.020 \mathrm{~g}$, respectively. In vitro disintegration test showed that the propolis powder that was loaded into the hard gelatine capsules disintegrated faster than the propolis powder loaded into the hard HPMC capsules, which were 1.7 to $7.8 \mathrm{~min}$ and 3.7 to $8.4 \mathrm{~min}$ in all four media solutions. Among the dissolution media tested, $1 \%$ SLS in water showed the highest release of flavonoid. The studies of an encapsulated form of propolis powder are recommended prior to the release of a dietary supplement or clinical trial investigational product to ensure its efficacy.
\end{abstract}

Key words: Propolis, Trigona thoracica, Freeze-drying, Capsule, Disintegration, Dissolution.

\section{INTRODUCTION}

In Malaysia, the growing interest of stingless beekeeping industry has opened up opportunities to explore the potential of bee products. In addition to honey, propolis also has great potential to be developed as supplementary material or health care products due to its medicinal properties. Propolis is produced by bees from substances collected from plants, buds, exudates of certain trees and plants. Propolis has been reported to possess antibacterial, anti-inflammatory, anti-oxidant and anesthetise activities. ${ }^{1-3}$ Propolis has been used by Greek and Roman physicians since ancient times as an antiseptic and curing agent in wound treatment and mouth disinfectant. In additions, propolis was established by the Persians as a drug capable of acting against eczemas, myalgia and rheumatism. ${ }^{4}$

Malaysian propolis is reported to be rich in phenolic acid and flavonoid content which leads to various biological properties. Previous researches proved that Malaysian propolis consists of biological activity that brings many therapeutic benefits to humans such as antimicrobial, antioxidant and antiinflammatory effects. ${ }^{5-7}$ A study reported that, there was a significantly positive high correlation between flavonoid content and antioxidant activities. ${ }^{8}$ The antioxidants are known to protect against oxidative stress,
Submission Date: 26-08-2020; Revision Date: 25-11-2020; Accepted Date: 29-01-2021

DOI: 10.5530/ijper.55.2.80 Correspondence:

Dr. Wan Nurul Huda Wan Zainal

Faculty of Chemical and

Process Engineering Technology, Universiti

Malaysia Pahang, Lebuhraya Tun Razak, 26300

Gambang, Kuantan, Pahang, MALAYSIA.

Phone no: +60-9-5492471

Email id:wannurulhuda@

ump.edu.my

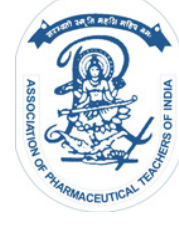

www.ijper.org 
which has been implicated in the development of several chronic diseases, such as cardiovascular disease and cancer. ${ }^{9}$ Nowadays in the market, propolis is available as dietary supplement or as health care products and can be found in few forms like capsule, liquid, liquid gel and spray aiming to act as antibacterial, antioxidant and antimicrobial. ${ }^{10-13}$

Propolis was mentioned in the London Pharmacopoeias in the $17^{\text {th }}$ century as an official drug. ${ }^{14}$ Propolis needs to be purified to eliminate impurities like wood, wax and dead bees before use. Besides, the amount that can be used is also very small because of its intense taste and unpleasant odour. ${ }^{15}$ It was reported that propolis was encapsulated using a spray-drying technique to mask the strong and unpleasant odour. ${ }^{16}$ However, spray drying could diminish the beneficial antioxidant property. ${ }^{17}$ Freeze-drying could be an alternative method to conserve the desirable qualities as well as extend the shelf life of propolis. Freeze-drying is a method based on the principle of sublimation, which is a process when a solid is changed into the gas phase without entering the liquid phase. The liquid sample is frozen at -40 to $-80^{\circ} \mathrm{C}$ prior to drying to solidify any liquid in the samples. This drying technique was used by pharmaceutical and food industries for delicate and heat-sensitive material. Even though freeze-drying is a complex and an expensive technique, it was reported that it yielded a high amount of phenolic contents as most of the phytochemicals are preserved. ${ }^{18}$ Zainol et al. ${ }^{19}$ studied the effect of different drying techniques on the flavonoid content of the herbal plant. The loss of flavonoid was found to be least in the freeze-dried sample compared to other drying techniques.

Evaluation of herbal product is necessary to ensure its quality and efficacy. Parameters for capsule finished product include mass uniformity, moisture content, disintegration time and dissolution study. ${ }^{20}$ However, scarce public data exist on the quality of propolis powder with regard to the in vitro disintegration and dissolution criteria. The quality and performance of such tests will greatly impact the outcome of the clinical investigations. ${ }^{21}$ To date, most of the pharmaceutical capsules available in the market are made of gelatine due to its gelforming characteristics and its excellent solubility in biological fluids. Capsules made from hydroxypropyl methylcellulose (HPMC) have recently been introduced as an attractive vegetarian alternative. The objective of this study was to convert propolis extract to powder obtained from Trigona thoracica species using a freezedrying technique. The effect of freezing temperature on the mass of propolis powder obtained and flow ability characteristics was investigated. In addition, the potential of propolis powder to be encapsulated in the hard gelatin capsules and HPMC capsules were evaluated in terms of in vitro disintegration and dissolution profile.

\section{MATERIALS AND METHODS Materials}

Raw propolis were obtained from species of stingless bee, Trigona thoracica from Kelantan Biotech Corporation Sdn. Bhd. Ethanol, aluminium chloride, potassium acetate, sodium acetate trihydrate, disodium hydrogen phosphate, potassium dihydrogen phosphate, hydrochloric acid, sodium lauryl sulfate and quercetin were purchased from Sigma Aldrich (St. Louis, USA). All the chemicals and reagents used in this study were of analytical grade. Two types of capsule were used in this study namely hard gelatine capsule and hard HPMC capsule.

\section{Preparation of extract}

Raw propolis was washed thoroughly with distilled water and air-dried. Then, the propolis was crushed and ground into small pieces. The extraction of propolis was carried out at a ratio of 1:10 (w:v). About $10 \mathrm{~g}$ of ground propolis was added in $100 \mathrm{~mL}$ of ultra-pure water in a beaker. The mixture was shaken at $70 \mathrm{rpm}$ at room temperature for one day. The water extract was then filtered using Whatman No. 1 filter paper. The propolis aqueous extract was stored in a chiller until further process. The flavonoid content of propolis was determined using an aluminium chloride colorimetric method and expressed as $\mu \mathrm{g} / \mathrm{ml}$ quercetin equivalent $(\mu \mathrm{g} / \mathrm{ml} \mathrm{QE})$ as described by Devequi-Nunes et al. ${ }^{22}$ with slight modifications. Quercetin was used as a standard. Quercetin was diluted in a solvent (25 to $200 \mathrm{~g} / \mathrm{mL}$ ) to prepare the calibration curve. To determine the TFC, $0.5 \mathrm{~mL}$ of propolis extract was mixed with $1.5 \mathrm{~mL}$ of extracting solvent, $0.1 \mathrm{~mL}$ of $10 \%(\mathrm{w} / \mathrm{v})$ aluminium chloride solution and $2.8 \mathrm{~mL}$ of distilled water. The solution was incubated for $30 \mathrm{~min}$ at room temperature and the absorbance of the solution was measured using Shimadzu UV-Vis Spectrophotometer UV-1800 at 415 $\mathrm{nm}$.

\section{Preparation of freeze-dried powder extract}

The purified propolis extract was frozen in a laboratory refrigerator (Thermo Scientific, United States). The freezing temperatures were varied to $-50^{\circ} \mathrm{C},-60^{\circ} \mathrm{C}$, $-70^{\circ} \mathrm{C}$ and $-80^{\circ} \mathrm{C}$. The $25 \mathrm{~mL}$ of propolis liquid extract was transferred in a $50 \mathrm{~mL}$ centrifuge tube and then placed in a laboratory refrigerator at a temperature 
of $-50^{\circ} \mathrm{C}$. The centrifuge tube was covered with an aluminium foil to ease the freezing process, to reduce the pressure in the centrifuge tube that could affect the freezing quality and also to avoid contamination. The freezing process was conducted for $48 \mathrm{hr}$.

The frozen propolis was transferred into a condenser-type freeze dryer to undergo the primary drying which is the sublimation process. The temperature and pressure for the primary drying process were automatically set by the equipment and the process commenced until the status bar turned from red to green. The process was conducted for $24 \mathrm{hr}$. The temperature and pressure were maintained throughout the process in order to ensure a smooth process.

At the end of primary drying, the secondary drying process began. In the secondary drying step, the temperature was increased to $35^{\circ} \mathrm{C}$. The vacuum pressure was reduced and maintained at the same level by the equipment automatically. The secondary process was continued for $24 \mathrm{hr}$ to complete the entire process. ${ }^{23}$ The process was completed when the status bar showed changes from red to green and the product appearance indicated dryness, where there were no powder residue sticking at the inner surface of the centrifuge tube. ${ }^{24}$ The same procedure was repeated for the samples frozen at $-60^{\circ} \mathrm{C},-70^{\circ} \mathrm{C}$ and $-80^{\circ} \mathrm{C}$. The mass of propolis powder obtained was determined.

\section{Flow ability test}

The flow ability test conducted was the angle of repose method with fixed height to obtain the angle of repose, $\theta$. About $5 \mathrm{~g}$ of the propolis powder was poured from a fixed height of $40 \mathrm{~mm}$ above the bench surface. A cone was formed and the height, $b$ of the granules forming the cone and the horizontal length, $r$ of the base was measured as shown in Figure 1. The angle of repose, $\theta$ was calculated using Equation 1.

$$
\theta=\tan ^{-1}\left(\frac{b}{r}\right)
$$

Where $b$ is the height of the granule and $r$ is the horizontal length of the base.

\section{Capsule filling}

Prior to encapsulation, the obtained propolis powder was sieved to have a uniform particle size to ease the flow ability of powder. Propolis powder was passed through a sieve with an aperture of $850 \mu \mathrm{m}$ as this is the ideal measure of particle size. ${ }^{25}$ The propolis powder was transferred into the semi-automated encapsulating machine (Njp200c, China) to punch into size one capsules. Then, the capsules were cleaned and polished

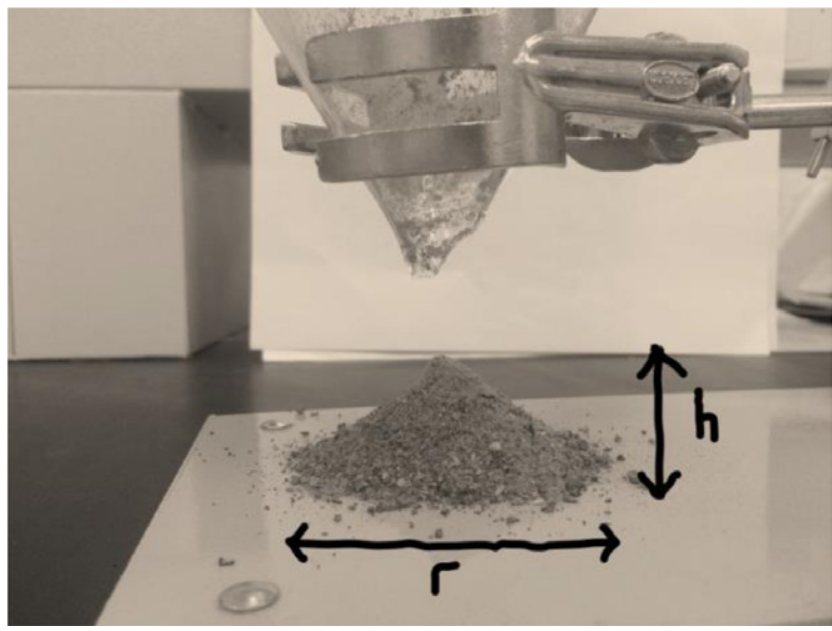

Figure 1: Angle of repose basic measurement setup.

using a gauze or cloth. In this study, 2 types of capsules were used, namely hard gelatine capsule and hard HPMC capsule.

\section{Determination of mass uniformity}

The determination of mass uniformity was performed based on the United State Pharmacopeia (USP). About 20 capsules were randomly selected and individually weighed. Next, each capsule was carefully opened and the content was removed. The emptied capsule was re-weighed. The mass of the content is the difference between the weighing. The average mass and percentage deviation were calculated using Equation 2 and Equation 3 , respectively. As per the USP specification, the percentage deviation is set to $\pm 7.5 \%$ for capsules with a mass greater than $300 \mathrm{mg}$. The capsule complies with the test if not more than two individual masses deviate from the average mass by more than the set percentage and none deviates by more than twice the percentage.

Average mass $=($ Total mass of 20 capsules $) / 20$

(Equation 2)

Percentage deviation $=(\mid$ individual mass - average mass $\mid$ / average mass $) \times 100 \%$ (Equation 3)

\section{In vitro disintegration test}

Capsule in vitro disintegration test was performed in a capsule disintegration tester (Electrolab Disintegration Testers 2 Station, India). Six capsules were randomly selected to perform the disintegration test. The disintegration test was conducted in four solution media namely pH $1.20 .1 \mathrm{M} \mathrm{HCl}, \mathrm{pH} 4.5$ acetate buffer, $\mathrm{pH}$ 6.8 phosphate buffer and $1 \%$ sodium lauryl sulfate (SLS) in water. One capsule was added to each tube and 
suspended in the beakers which contain the media solution. Throughout the experiment, the temperature was maintained at $37 \pm 2^{\circ} \mathrm{C}$. After $30 \mathrm{~min}$, the basket was lifted from the media solution. The capsules in the basket were observed. The capsules were considered disintegrated if there are no fragments of the capsule shell. If one or two capsules out of the six tubes fails to disintegrate completely, the test should be repeated once again with the addition of two capsules into each of the six tubes, making the total number of capsules in the apparatus to be 12 capsules. The requirement is met if not less than 16 out of 18 capsules tested are disintegrated.

\section{In vitro dissolution test}

In vitro dissolution test of all freeze-dried propolis powder contained in hard gelatine capsules and hard HPMC capsules was performed using paddle dissolution apparatus (Electrolab Dissolution Tester 8 Station (EDT-08Lx, India). The test was employed in 900 $\mathrm{mL}$ of media solution and conducted in four media solutions namely $\mathrm{pH} 1.2$ hydrochloric acid $(\mathrm{HCl}), \mathrm{pH}$ 4.5 acetate buffer, $\mathrm{pH} 6.8$ phosphate buffer and $1 \%$ SLS in water. The test was conducted at a rotational speed of $75 \mathrm{rpm}$ and temperature of $37 \pm 0.5^{\circ} \mathrm{C}$. The dissolution profiles were determined based on the quantification of flavonoid content from the capsules dissolved in a media solution. The flavonoid content in a media solution was analysed using a UV-Vis spectrophotometer (Shimadzu, UV-2600) at a wavelength of $410 \mathrm{~nm}$. At time interval of $5 \mathrm{~min}, 5 \mathrm{~mL}$ of sample was withdrawn from the dissolution media and replaced by $5 \mathrm{~mL}$ of fresh media solution.

\section{RESULTS AND DISCUSSION}

\section{Effect of freezing temperature on the mass propolis powder produced and flow ability characteristics}

The flavonoid content of propolis powder was determined to be $98.94 \mathrm{ug} / \mathrm{mL}$ QE. The mass of propolis powder obtained after freeze-drying and flow ability characteristics of the powder are tabulated in Table 1.

\begin{tabular}{|c|c|c|c|}
\hline \multicolumn{4}{|c|}{ Table 1: Mass of propolis powder obtained at } \\
different freezing temperature.
\end{tabular}

The mass was determined based on $100 \mathrm{~mL}$ propolis extract. The amount of propolis powder produced after freeze-drying decreased with decreasing of freezing temperature from $-50^{\circ} \mathrm{C}$ to $-80^{\circ} \mathrm{C}$. Prior to the freezedrying, the raw propolis was extracted using water as a solvent. The propolis liquid extracts contain both liquid water as a solvent and solute in the form of solid. Presence of solid reduced the freezing point of water, which is normally $0^{\circ} \mathrm{C}$ for pure water. Cooling the propolis liquid extracts at temperature below $0^{\circ} \mathrm{C}$ resulted in the formation of solid water. However, there remained unfrozen liquid water that contains the solid (solute). As the freezing temperatures decreased, more water was solidified and less unfrozen liquid was left. In the freeze-drying process, the solid water sublimed and left behind the solute. This explained why the mass of propolis powder obtained reduced with the decrease of freezing temperature.

The angle of repose is measured to determine the flow ability characteristic of propolis powder. According to the United States Pharmacopeia, ${ }^{26}$ angle of repose between 25 to $30^{\circ}$ represents an excellent powder flow, between 31 to $35^{\circ}$ has good flow ability characteristics and between 36 to $40^{\circ}$ exhibited fair flow ability characteristic. For values higher than $41^{\circ}$, the material has poor flow ability characteristic. The obtained propolis powder showed angle of repose values between $26^{\circ}$ to $48^{\circ}$. The propolis powder frozen at the temperature of $-50^{\circ} \mathrm{C}$ and $-60^{\circ} \mathrm{C}$ exhibited passable flow ability characteristic while $-70^{\circ} \mathrm{C}$ has fair flow ability characteristic. The propolis powder obtained from $-80^{\circ} \mathrm{C}$ showed an excellent flow ability characteristic. Therefore, for encapsulation purpose, the propolis powders were produced at $-80^{\circ} \mathrm{C}$ freezing temperature.

\section{Mass uniformity}

The mass and percentage variation results for hard gelatine capsules and hard HPMC capsules are summarized in Table 2. Based on the results, all the hard gelatine capsules and hard HPMC capsules were within the accepted standards of the United States Pharmacopeia. The average mass for hard gelatine capsules was 0.5578 $\pm 0.019 \mathrm{~g}$, with an acceptable range from $0.5160 \mathrm{~g}$ to 0.5996 g. The minimum and maximum mass of hard gelatine capsules were $0.5312 \mathrm{~g}$ and $0.5903 \mathrm{~g}$, respectively. Whereas, for the hard HPMC capsules, the average mass was $0.5559 \pm 0.020 \mathrm{~g}$, with an acceptable range from $0.5142 \mathrm{~g}$ to $0.5976 \mathrm{~g}$. The minimum and maximum mass of hard HPMC capsules were $0.5210 \mathrm{~g}$ and $0.5888 \mathrm{~g}$, respectively. Therefore, all hard gelatine capsules and hard HPMC capsules tested in this study have a uniform mass and passed the mass uniformity test. 


\section{Table 2: Average mass and percentage deviation of hard gelatine capsules} and hard HPMC capsules.

\begin{tabular}{|c|c|c|c|c|c|}
\hline \multicolumn{3}{|c|}{ Hard Gelatine Capsule } & \multicolumn{3}{c|}{ Hard HPMC Capsule } \\
\hline No & $\begin{array}{c}\text { Mass of Intact } \\
\text { Capsule (g) }\end{array}$ & $\begin{array}{c}\text { Percentage } \\
\text { deviation (\%) }\end{array}$ & No & $\begin{array}{c}\text { Mass of Intact } \\
\text { Capsule (g) }\end{array}$ & $\begin{array}{c}\text { Percentage } \\
\text { deviation (\%) }\end{array}$ \\
\hline 1 & $0.5582 \pm 0.009$ & 0.08 & 1 & $0.5413 \pm 0.004$ & 2.62 \\
\hline 2 & $0.5702 \pm 0.006$ & 2.22 & 2 & $0.5461 \pm 0.004$ & 1.76 \\
\hline 3 & $0.5432 \pm 0.003$ & 2.61 & 3 & $0.5417 \pm 0.007$ & 2.56 \\
\hline 4 & $0.5455 \pm 0.006$ & 2.21 & 4 & $0.5814 \pm 0.005$ & 4.59 \\
\hline 5 & $0.5903 \pm 0.003$ & 5.83 & 5 & $0.5614 \pm 0.002$ & 0.99 \\
\hline 6 & $0.5704 \pm 0.002$ & 2.26 & 6 & $0.5556 \pm 0.004$ & 0.05 \\
\hline 7 & $0.5788 \pm 0.003$ & 3.77 & 7 & $0.5351 \pm 0.007$ & 3.75 \\
\hline 8 & $0.5638 \pm 0.004$ & 1.08 & 8 & $0.5281 \pm 0.006$ & 5.00 \\
\hline 9 & $0.5825 \pm 0.005$ & 4.43 & 9 & $0.5210 \pm 0.003$ & 6.28 \\
\hline 10 & $0.5446 \pm 0.013$ & 2.37 & 10 & $0.5708 \pm 0.003$ & 2.68 \\
\hline 11 & $0.5596 \pm 0.002$ & 0.32 & 11 & $0.5545 \pm 0.008$ & 0.25 \\
\hline 12 & $0.5351 \pm 0.004$ & 4.06 & 12 & $0.5888 \pm 0.009$ & 5.92 \\
\hline 13 & $0.5349 \pm 0.007$ & 4.10 & 13 & $0.5444 \pm 0.007$ & 2.07 \\
\hline 14 & $0.5312 \pm 0.004$ & 4.76 & 14 & $0.5635 \pm 0.006$ & 1.37 \\
\hline 15 & $0.5526 \pm 0.013$ & 0.93 & 15 & $0.5298 \pm 0.007$ & 4.69 \\
\hline 16 & $0.5817 \pm 0.001$ & 4.29 & 16 & $0.5565 \pm 0.006$ & 0.10 \\
\hline 17 & $0.5434 \pm 0.006$ & 2.59 & 17 & $0.5702 \pm 0.010$ & 2.57 \\
\hline 18 & $0.5776 \pm 0.003$ & 3.55 & 18 & $0.5847 \pm 0.004$ & 5.19 \\
\hline 19 & $0.5599 \pm 0.004$ & 0.37 & 19 & $0.5576 \pm 0.011$ & 0.30 \\
\hline 20 & $0.5333 \pm 0.004$ & 4.39 & 20 & $0.5854 \pm 0.007$ & 5.31 \\
\hline
\end{tabular}

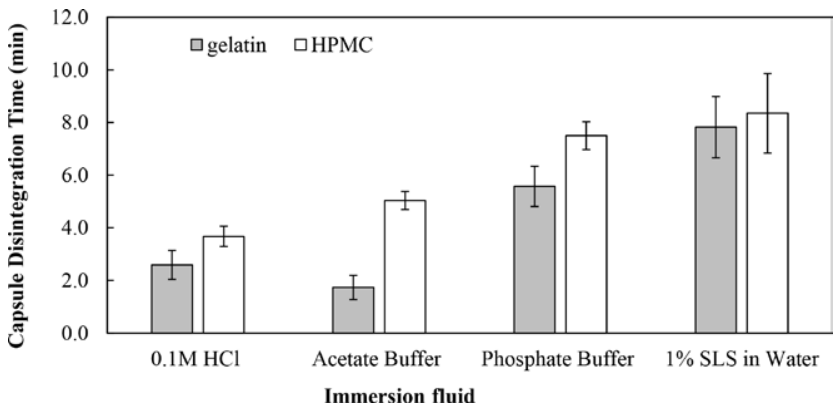

Figure 2: Disintegration time of freeze-dried propolis powder in hard gelatine capsules and hard HPMC capsules.

\section{In vitro disintegration test}

The disintegration test was conducted to determine the time taken for the oral dosage to completely disintegrate as shown on Figure 2. It was observed that the freezedried propolis powder in capsules, hard gelatine and hard HPMC released their content in all four media solutions within $10 \mathrm{~min}$ and no residue was remained at the end of the test. This showed that all the tested capsules complied with the test according to the USP requirements for disintegration of dietary supplement. The freeze-dried propolis powder filled in the hard gelatine capsules disintegrated rapidly (1.7 to $7.8 \mathrm{~min}$ ) as compared to the hard HPMC capsules (3.7 to $8.4 \mathrm{~min}$ ) in all four media solutions. The delay in the disintegration of hard HPMC capsules was notable especially in an acetate buffer as compared to hard gelatine capsules. However, in $1 \%$ SLS in water, the disintegration of both capsules was comparable. Also, it can be seen that the disintegration time for both capsules increased with increasing of $\mathrm{pH}$ of the media solution. The disintegration time of both hard gelatine capsules and hard HPMC capsules was 2.6-3.7 $\mathrm{min}$ in $0.1 \mathrm{M} \mathrm{HCl}, 1.7-5.0 \mathrm{~min}$ in acetate buffer, 5.6-7.5 $\mathrm{min}$ in phosphate buffer and 7.8-8.4 $\mathrm{min}$ in 1 $\%$ SLS in water. This exhibited that the disintegration of the hard gelatine capsules and hard HPMC capsules was dependent on the $\mathrm{pH}$ of the media solution. The results were in good agreement with previously reported study. ${ }^{21}$

The difference in disintegration behaviour of freeze-dried propolis powder in hard gelatine capsules and hard HPMC capsules could be due to the different capsule properties. In order for the propolis powder to begin to disintegrate, the capsule must be opened first before the propolis powder can have established contact with the media solution. HPMC is derived from vegetable cellulose which is moisturized quickly, but swells and takes longer time to disintegrate at body temperature. On the other hand, gelatine capsule is soluble in biological fluids at 
body temperature and can release its content quickly. ${ }^{27}$ This explains why freeze-dried propolis powder in hard gelatine capsules disintegrated faster than in hard HPMC capsules.

\section{In vitro dissolution test}

The dissolution profile of freeze-dried propolis powder in the hard gelatine capsule and hard HPMC capsule in the $0.1 \mathrm{M} \mathrm{HCl}$, acetate buffer, phosphate buffer and 1 $\%$ SLS in water are presented in Figures 3-6, respectively. In the $0.1 \mathrm{M} \mathrm{HCl}$, the hard gelatine capsule and hard HPMC capsule achieved the maximal release at $30 \mathrm{~min}$ by releasing, respectively, $8.1 \mu \mathrm{g} / \mathrm{mL}$ and $27.1 \mu \mathrm{g} / \mathrm{mL}$ of flavonoids at the end of the dissolution assay. Whereas in the acetate buffer, the maximal release of the flavonoid occurred at $25 \mathrm{~min}$ in which propolis powder in the hard gelatine capsule and hard HPMC capsule released about $19.2 \mu \mathrm{g} / \mathrm{mL}$ and $9.9 \mu \mathrm{g} / \mathrm{mL}$ of flavonoid, respectively. In the phosphate buffer, the propolis powder in the hard gelatine capsule reached the maximal release of flavonoid at $25 \mathrm{~min}$ and released $21.7 \mu \mathrm{g} / \mathrm{mL}$ of flavonoid, whereas for the hard HPMC capsule, the maximal release was achieved at $30 \mathrm{~min}$ and released $31.7 \mu \mathrm{g} / \mathrm{mL}$ of flavonoid at the end of the dissolution assay. For $1 \%$ SLS in water, propolis powder in the hard gelatine capsule and hard

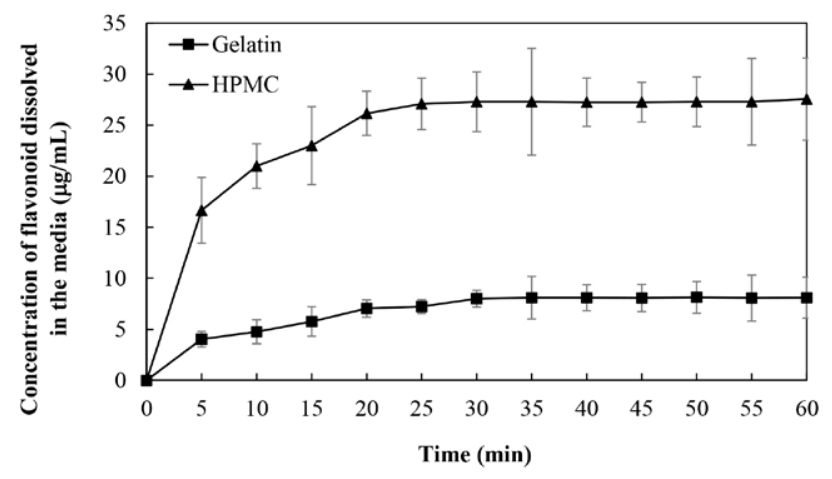

Figure 3: The dissolution profile in $0.1 \mathrm{M} \mathrm{HCl}(\mathrm{pH} \mathrm{1.2)} \mathrm{media}$ solution for hard gelatine capsule and hard HPMC capsule.

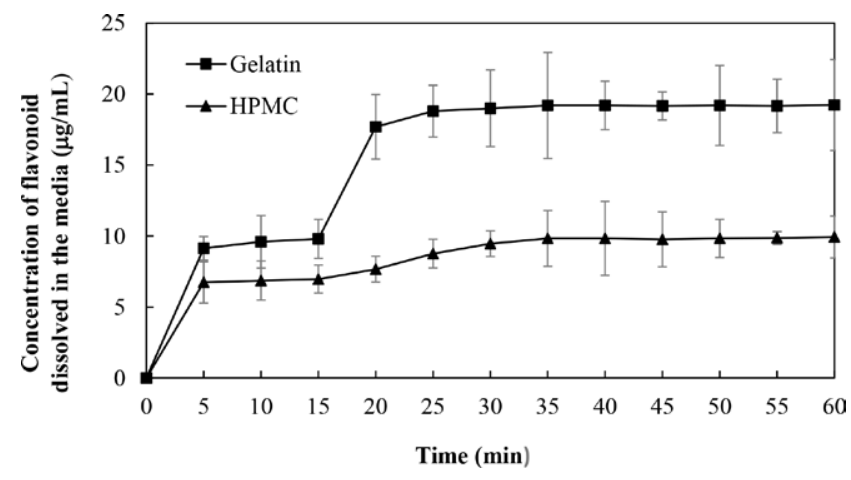

Figure 4: The dissolution profile in acetate buffer $(\mathrm{pH} 4.5)$ media solution for hard gelatine capsule and hard HPMC capsule.

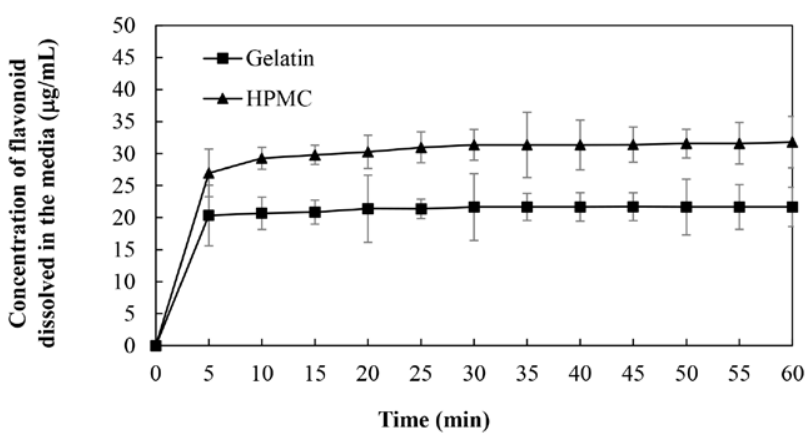

Figure 5: The dissolution profile in phosphate buffer ( $\mathrm{pH} \mathrm{6.8)}$ media solution for hard gelatine capsule and hard HPMC capsule.

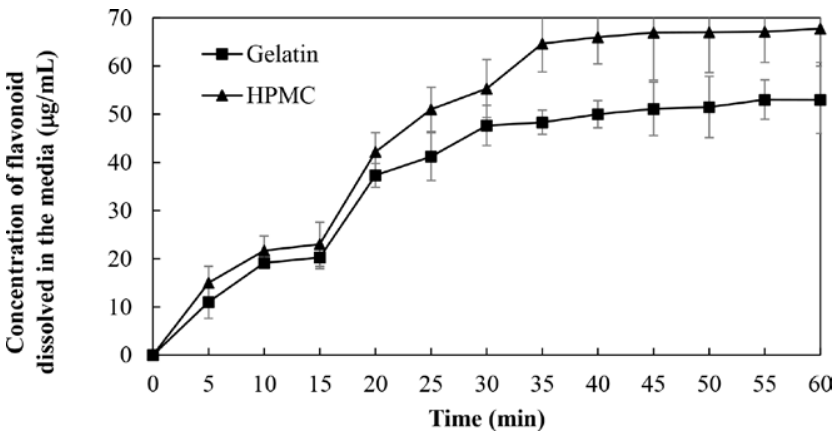

Figure 6: The dissolution profile in $1 \%$ SLS in water media solution for hard gelatine capsule and hard HPMC capsule.

HPMC capsule reached the maximal release at $30 \mathrm{~min}$ and $35 \mathrm{~min}$ by releasing $53.0 \mu \mathrm{g} / \mathrm{mL}$ and $67.8 \mu \mathrm{g} / \mathrm{mL}$ of flavonoid, respectively, at the end of the dissolution assay. No residues of the capsule shell were remained in the sinker at the end of the experiment.

Different solution media presented different dissolution profile to the propolis powder in the hard gelatine capsule and hard HPMC capsule. ${ }^{28}$ Overall, all of the tested capsules reached the maximal release at the time range of 25 to 35 min with the hard gelatine capsule exhibiting a faster release compared to the hard HPMC capsule. Among the dissolution media tested, $1 \%$ SLS in water showed the highest release of flavonoid. This showed that water is the most suitable media to dissolve the flavonoid due to its polarity and degree of polymerization of flavonoid compounds. Based on the study, it was also shown that it is possible to control the release of flavonoid using different type of capsules. The incorporation of propolis powder into the hard HPMC capsules delayed the release of the flavonoid. This behaviour could be explained as when the hard HPMC capsule was in contact with the dissolution media, it swelled and formed a gelled layer that controlled the subsequent entrance of water into the matrix. ${ }^{17}$ The low speed of water penetration into the matrix had slowed down the release of flavonoid. In addition, the problems of hygroscopic materials in 
which sensitive to humidity and interaction between the materials and gelatine could be controlled using hard HPMC capsules.

\section{CONCLUSION}

In conclusion, the propolis powder obtained from the stingless bee Trigona thoracica species was successfully produced. The freezing temperature of $-80^{\circ} \mathrm{C}$ produced the lowest yield of propolis powder but with the excellent flow ability characteristics. Propolis powder exhibited a potential to be encapsulated in hard gelatine capsules and hard HPMC capsules. Both hard gelatine capsules and hard HPMC capsules passed the mass uniformity, in vitro disintegration and dissolution tests. Future animal studies, stability studies and clinical trial investigational of the propolis capsules are necessary to be conducted to examine the safety and efficacy prior to the release of propolis capsule as a dietary supplement.

\section{ACKNOWLEDGEMENT}

The authors would like to thank Universiti Malaysia Pahang for financing the project through UMP Internal Grant Scheme (RDU1703116) and laboratory facilities.

\section{CONFLICT OF INTEREST}

The authors declare that there is no conflict of interest regarding the publication of this article.

\section{ABBREVIATIONS}

HPMC: Hydroxypropyl methylcellulose; SLS: Sodium lauryl sulfate; USP: United State Pharmacopeia; HCl: Hydrochloric acid.

\section{REFERENCES}

1. Awang N, Ali N, Abd MFA, Hamzah S, Abd RSB. Total flavonoids and phenolic contents of sticky and hard propolis from 10 species of Indo-Malayan stingless bees. Malaysian J Anal Sci. 2018;22(5):877-8.

2. Aminimoghadamfarouj N, Nematollahi A. Propolis diterpenes as a remarkable bio-source for drug discovery development: A review. Int $\mathrm{J}$ Mol Sci. 2017;18(6):1290.

3. Sforcin JM, Bankova V, Kuropatnicki AK. Medical benefits of honeybee products. Evid Based Complement Alternat Med. 2017;1-2. Article ID 2702106.

4. Silva-Carvalho, R, Baltazar F, Almeida-Aguiar C. Propolis: A complex natural product with pletora of biological activities that can be explored for drug development. Evid Based Complement Alternat Med. 2015. Article ID 206439.

5. Yusop SA, Sukairi AH, Wan SWMA, Asruddin MR. Antioxidant, antimicrobial and cytotoxicity activities of propolis from Beladin, Sarawak stingless bees Trigona itama extract. Mater Today-Proc. 2019;1752-60.
6. Asem N, Abdul GNA, Abd HNH, Omar EA. Correlation between total phenolic and flavonoid contents with antioxidant activity of Malaysian stingless bee propolis extract. J Apicult Res. 2019. doi:10.1080/00218839.2019.1684050.

7. Nna VU, Abu BAB, MdLazin, MR, Mohamed M. Antioxidant, anti-inflammatory and synergistic anti-hyperglycemic effects of Malaysian propolis and metformin in streptozotocin-induced diabetic rats. Food Chem Toxicol. 2018;120:305-16.

8. Ozdal T, Ceyla FD, Eroglu N, Kaplan M, Olgun EO, Capanoglu E. Investigation of antioxidant capacity, bioaccessibility and LC-MS/MS phenolic profile of Turkish propolis. Food Res Int. 2019;122:528-9.

9. DaSilva FC, Garcia CSC, Gambato G, DeSouza MDO, Salvador M, Moura S, et al. Chemical characterization, antioxidant and cytotoxic activities of Brazilian red propolis. Food Chem Toxicol. 2013;52:137-6.

10. Natonic.com [homepage on the internet]. Australia [retrieved $2020 \mathrm{Dec} 4$ ]. Available from: https://natonic.com.au/en/healthy-care-propolis-2000mg-200capsules-twin

11. Iherb.com [homepage on the internet]. Malaysia [retrieved 2020 Dec 4]. Availablefrom:https://my.iherb.com/pr/California-Gold-Nutrition-Bee-Propolis2X-Concentrated-Extract-500-mg-90-Veggie-Caps/61839

12. Lazada.com [homepage on the internet]. Malaysia [retrieved 2020 Dec 4] Available from: https://www.lazada.com.my/products/vita-health-bee-propolis2-x-120-softgels-i507466126-s960464349.html

13. Euyansang.com [homepage on the internet]. Malaysia [retrieved $2020 \mathrm{Dec} 4$ ] Available from: https://www.euyansang.com.my/en_MY/brazilian-green-propolis955616010212.html

14. Wagh VD. Propolis: A wonder bees product its pharmacological potentials. Adv Pharmacol Sci. 2013. Article ID 308249

15. Habryka C, Socha R, Juszczak L. The effect of enriching honey with propolis on the antioxidant activity, sensory characteristics and quality parameters. Molecules. 2020;25(5):1176-18.

16. Busch VM, Pereyra-Gonzalez A, Šegatin N, Santagapita PR, Ulrih NP, Buera MP. Propolis encapsulation by spray drying: Characterization and stability. LWT-Food Sci Tech. 2017;75:227-9.

17. Gomes WF, França FRM, Denadai M, Andrade JKS, Oliveira EMDS, DeBrito ES, et al. Effect of freeze- and spray-drying on physico-chemical characteristics, phenolic compounds and antioxidant activity of papaya pulp. J Food Sci Technol. 2018;55(6):2095-8.

18. Azwanida NN. A review on the extraction methods use in medicinal plants, principle, strength and limitation. Med Aromat Plants. 2015;4(3):1-6.

19. Zainol MKM, Abdul-Hamid A, Abu BF, Pak DS. Effect of different drying methods on the degradation of selected flavonoids in Centella asiatica. Int Food Res J. 2009;16(4):531-8.

20. Soni HK, Ribadiya NC, Bhatt SB, Sheth NR. Evaluation of herbal formulation (capsule) containing ashwagandha as a single herb with their nutritional value determination. Int J Appl Biol and Pharm Technol. 2010;1(3):960-8.

21. Glube N, Moos VL, Duchateau G. Capsule shell material impacts the in vitro disintegration and dissolution behaviour of a green tea extract. Results Pharma Sci. 2013;3:1-6.

22. Devequi-Nunes D, Machado BAS, DeAbreu BG, Silva JR, DaSilva DF, DaRocha JL, et al. Chemical characterization and biological activity of six different extracts of propolis through conventional methods and supercritical extraction. Plus One. 2018;13(2):1-20.

23. DoNascimento TG, DaFonseca SP, Farias AL, DaGuerra RL, DeCristina C, Moraes $\mathrm{PI}$, et al. Polymeric nanoparticles of brazilian red propolis extract: preparation, characterization, antioxidant and leishmanicidal activity. Nanoscale Res Lett. 2016;11(301):1-16.

24. A Guide To Freeze Drying for the Laboratory: An industry service publication. 2020. [retrieved 2020 March 16] Available from: http://biotecnologiaindustrial. fcen.uba.ar/wp-content/uploads/2010/03/freezedrying.pdf

25. Honary S, Ebrahimi P, Naghibi F, Chaigani M. Controlled release formulation of indomethacin prepared with bee glue extracts. Trop J Pharm Res. 2011;10(5):543-8.

26. United States Pharmacopei: Powder flow 30(6) Harmonization:<1174> [retrieved 2020 March 20] Available from: http://www.usp.org/sites/default/ files/Harmonization/Gen-Chapter/g05_pf_30_6_2004.pdf

27. Weigert GG, Gomes APIP. Evaluation of hard gelatin capsules and hydroxypropyl methylcellulose containing Ampicillin. Quím Nova. 2012;35(2):286-5.

28. Al-Tabakha MM. HPMC capsules: Current status and future prospects. J Pharm Pharm Sci. 2010;13(3):428-15. 


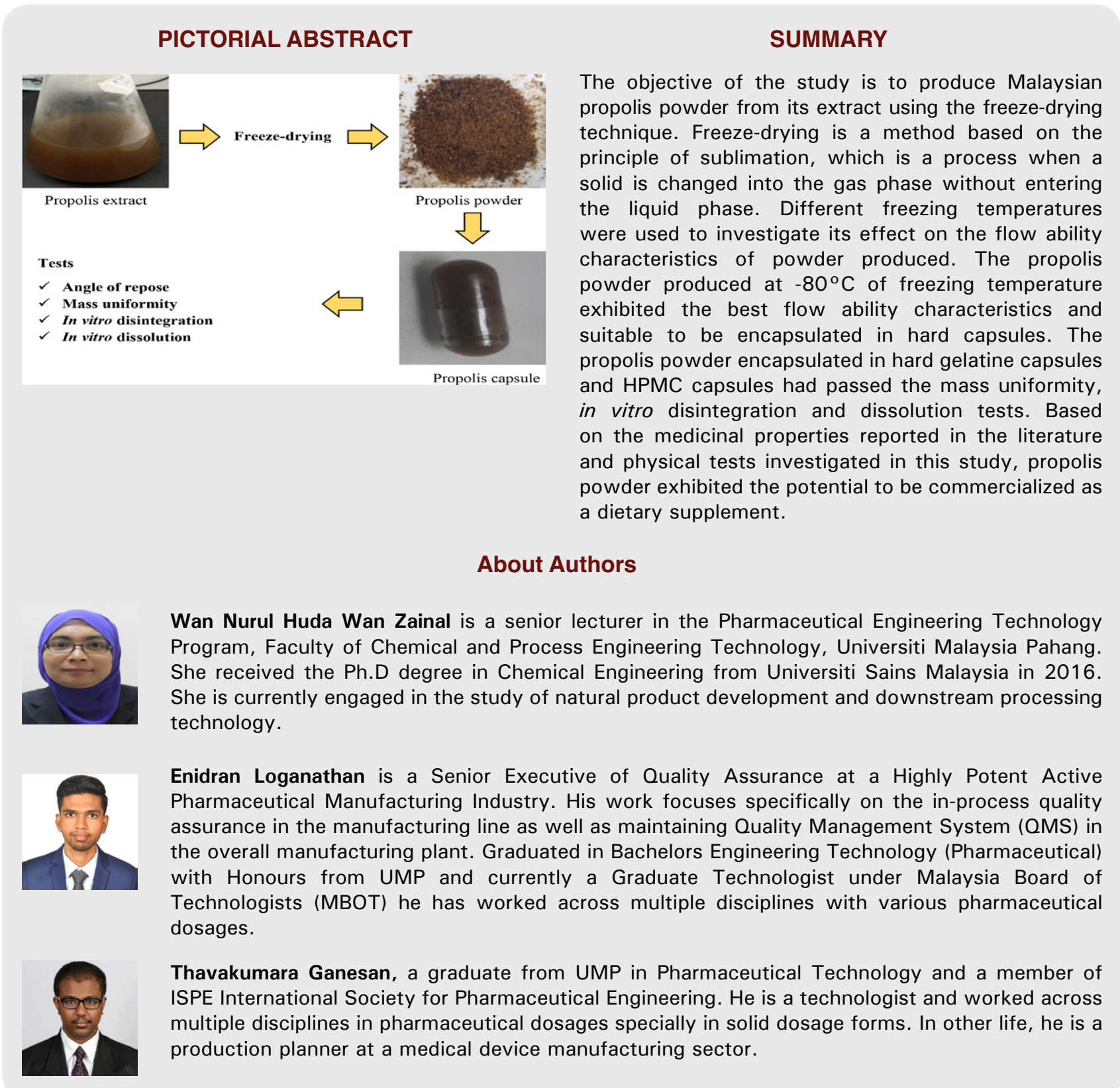

Cite this article: Zainal WNHW, Loganathan E, Ganesan T. Encapsulation of Freeze-dried Propolis Powder: Study of in vitro Disintegration and Dissolution. Indian J of Pharmaceutical Education and Research. 2021;55(2):428-35. 